\title{
Outpatient appointments and waiting time in a tertiary health facility in Jos
}

\author{
Akosu $\mathrm{TJ}^{1}$, Afolaranmi $\mathrm{T}^{1}$, Usar $\mathrm{JI}^{1}$ and Odunze $\mathrm{P}^{2}$ \\ ${ }^{1}$ Department of Community Medicine, University of Jos, Jos \\ ${ }^{2}$ Department of Community Medicine, Jos University Teaching Hospital, Jos, Nigeria \\ Correspondence: Akosu TJ. E-mail: akosu2002@yahoo.co.uk
}

\begin{abstract}
Background.The system used to schedule outpatient appointments affects the time clients wait before seeing their doctors. The purpose of this study was to determine the appointment system used in Jos University Teaching Hospital and the waiting time before consultation.

Methods .A semi- structured interviewer administered questionnaire was used to collect data from 202 clients selected by multi-stage sampling technique. A trained observer recorded the time patients waited before seeing their doctor.

Results. Single block appointment system was used to schedule outpatient appointments for all the subjects. Median waiting time was 220 minutes (IQR 172.50 - 296.25 minutes). There was a significant relationship between type of Clinic and waiting time $(p=0.0003)$. Most of the subjects $(79.2 \%)$ were not happy with the time they spent waiting to see a doctor although about 57 percent of them were generally satisfied with the services they received in the Hospital.

Conclusion. Jos University Teaching Hospital practices block appointment system that results in long waiting time. Urgent action is needed to change this practice that contributes to patient's dissatisfaction.
\end{abstract}

Keywords: Out-patient, Waiting time, Block appointment, JUTH.

\section{Introduction}

According to the British Patient Charter, the recommended maximum waiting time for a patient in an out-patient Clinic is 30 minutes. ${ }^{1}$ When medical practice continually minimizes client waiting time, it results in overall improvement in patient satisfaction. ${ }^{2-4}$ Despite the aforementioned recommendation, waiting time in various health facilities across Nigeria remains unacceptably long and accounts for one of the numerous factors responsible for poor uptake of health services. ${ }^{5-8,9,10}$ For instance, studies in Sokoto, Ogun and Lagos states have reported waiting times ranging from 42.89 minutes to 240 minutes.

Long waiting time is a major source of patient dissatisfaction and adversely affect patient's compliance with treatment regimens and clinical outcomes. ${ }^{11}$ Other possible negative consequences of long waiting time include loss of man hours for patients, huge economic losses for the hospital and nation in general. Also, patients are exposed to nosocomial pathogens and infections since patients with infectious diseases often wait in the same waiting hall with others. Respiratory tract infections including tuberculosis and other air-borne diseases can be easily disseminated during the long waiting time. This problem can be mitigated by several measures including increasing the number of physicians attending to clients in the outpatient clinics. ${ }^{13}$ This of course requires an increase in the staff strength of the 
facility with attendant budgetary requirement. Other ways to reduce waiting time include modified block scheduling and individual scheduling. In modified block scheduling a smaller number of patients are assigned to smaller segments of time throughout the day, such as hourly. ${ }^{14}$ Individual scheduling, the most commonly used scheduling technique in the USA occurs when a single patient is scheduled for a specific point in time, with the timing of the appointments determined according to the supply of care providers. ${ }^{15}$ In Nigeria however, observation by the authors indicate that most public health facilities use the single block scheduling method in which all patients to be seen during the clinic are scheduled at the same time such as morning or afternoon and then seen on a first-come first-served basis within that time frame. Patients are usually given 7.30 am or 8.00 am appointment yet some of them are seen by the doctor as late as $3.00 \mathrm{pm}$. The reasons for this delay which is wasteful and sometimes harmful to the patient have not been thoroughly studied and documented in our setting. The purpose of this study therefore was to determine the type of outpatient appointment system in use and assess patient waiting time in Jos University Teaching Hospital Jos, Nigeria.

\section{Methods}

A cross-sectional study was carried out in Jos University Teaching Hospital with 620 beds located in Jos the capital of Plateau state. The study population consisted of patients attending the out-patient clinics and the record officers responsible for scheduling out-patient appointments. The sample size was determined using the sample size formula for populations less than 10,000 and a prevalence of the factor under study of $84 \%$ (from a previous study) and at a significance of $p<0.05$ to arrive at a minimum sample size of 196 and adjusted to202..$^{16,17}$

Data was collected in February and March 2018. Each clinic was visited on consecutive clinic days until the required sample size was attained. A multistage sampling technique was used to select the study subjects. Three outpatient Department clinics, the General Outpatient Department clinic (GOPD), Medical Outpatient Department clinic (MOPD) and the Surgical Outpatient Department clinic (SOPD) were selected by balloting from the list of outpatient clinics in the hospital. A systematic sampling method was then used to select study subjects in each of the selected clinics using the clinic's appointment register. The number of subjects selected from each of the clinics was proportional to the size of the patient population in that clinic. The patient population in each clinic was estimated by adding the total number of patients booked for the clinic in the preceding three months. The sampling interval in each clinic was determined using the number of patients to be selected from the clinic and the patient population in that clinic. The first patient was selected by balloting.

All adult clients of selected outpatient clinics who were attending the clinic on appointment were eligible to participate in the study. All the record officers responsible for scheduling appointments in the selected clinics were also enrolled in the study. Those who met the inclusion criteria but refused consent were excluded. Participants were informed about the study objectives and procedures and an informed consent obtained before being enrolled. The study was approved by the Jos University Teaching Hospital's Institutional Health Research Ethics Committee. 
A semi structured interviewer administered questionnaire was used to collect data from patients about the time of their appointment and their satisfaction with the hospital's appointment system, the waiting time and the services they receive from the hospital. The appointment time of the patients was confirmed by looking at their appointment cards.

Four trained observers, two for the GOPD clinic and one each for the MOPD and SOPD were engaged to record the time patients walked into the waiting hall of the outpatient department and the time they entered the consulting room to see a doctor. This information was used to determine the waiting time before consultation. A semi-structured interviewer administered questionnaire was also used to collect data about the type of appointment from the record officers responsible for scheduling appointments in the studied clinics. Data was analyzed using the Statistical Package for Social Sciences (SPSS) version 17. The data was skewed so the Kruskal Wallis test was used to test for relationship between type of clinic and median waiting time.

\section{Results}

Two hundred and two patients and ten record officers were studied. Most of the patients were young, males and married. Table 1 shows the socio-demographic characteristics of the study subjects. All the record officers were practicing single block appointment system (Table 2). All the subjects were given either 7.30 am or $8.00 \mathrm{am}$ appointment in line with this appointment system (Table 3 ). The waiting time range was 40-440 minutes with a median of 220 minutes (IQR 172.50 296.25 minutes). There was a significant relationship between type of clinic and waiting time (Table 4). Most of the subjects $(79.2 \%)$ were not happy with the time they had to wait to see a Doctor although 57 percent of them were satisfied with the other services they received in the Hospital. Technical competence of the Doctors was the commonest reason given for satisfaction with the Hospital's services while waiting time was the commonest reason given for dissatisfaction followed by the attitude of record staff/misplacement of patients' folders (Tables 5 and 6).

Table 1. Relationship between type of clinic attended and waiting time.

\begin{tabular}{lcccc}
\hline Parameters & n & $\begin{array}{c}\text { Waiting Time (Minutes) } \\
\text { Median (IQR) }\end{array}$ & Test Statistics & p-value \\
\hline Clinic Type & & & & \\
GOPD & 144 & $210.0(173.0-280.0)$ & & \\
MOPD & 59 & $257.0(205.0-315.0)$ & $15.997^{*}$ & 0.0003 \\
SOPD & 29 & $185(140.0-215.0)$ & & \\
\hline
\end{tabular}

* Kruskal Wallis Test

Table 2: Waiting time and respondent's satisfaction with waiting time $(n=202)$.

\begin{tabular}{lc}
\hline Waiting time (Minutes) & Freq.(\%) \\
\hline$<220$ & $107(53.0)$ \\
$=220$ & $95(47.0)$ \\
& Median waiting time \\
Mean waiting time & 220 minutes IQR $172.50-296.25$ minutes \\
$230.27 \pm 85.58$ minutes & \\
Satisfaction with waiting time & Freq, (\%) \\
Happy & \\
Unhappy & $42(20.8)$ \\
& $160(79.2)$ \\
\hline
\end{tabular}


Table 3: Main Reasons for satisfaction/dissatisfaction with the hospital's services*

\begin{tabular}{llc}
\hline Reason & Satisfaction & \\
\hline & Yes & No \\
& Freq.(\%) & Freq. (\%) \\
Waiting time & $17(4.8)$ & $75(86.2)$ \\
Technical skill of Doctors & $73(63.5)$ & $2(2.3)$ \\
Cleanliness of the hospital & $17(14.8)$ & $1(1.1)$ \\
Friendliness of the staff & $6(5.2)$ & $2(2.3)$ \\
Record officer's performance & $2(1.7)$ & $7(8.0)$ \\
Total & $\mathbf{1 1 5}$ & $\mathbf{8 7}$ \\
\hline
\end{tabular}

*Multiple responses not allowed.

\section{Discussion}

This study shows that Jos University Teaching Hospital practices single block appointment system, all the patients were given early morning appointment $7.30 \mathrm{am}$ or $8.00 \mathrm{am}$ and the patients were seen by doctors on a first come, first served basis. This appointment system is no longer used in health facilities in developed countries and across some private hospitals in Nigeria. ${ }^{15}$ The Block method places no value on patients' time since it requires them to come congregate at the appointed time, before the commencement of the clinic, and then wait for the clinic to start before they are attended to ${ }^{18}$ To obtain a good position on the waiting line, some patients arrive a couple of hours before the commencement of the clinic, further increasing their waiting time. It also makes it difficult for physicians to plan since they have no idea of when they would see the last patient of the day.

In this study the waiting time was expectedly long, 220 minutes (IQR 172.5296.25) since all the patients were scheduled early in the morning. This is higher than the waiting time recorded in the hospital in previous studies. ${ }^{16}$ It is much higher than the time recorded in the General Outpatient Department of Lagos University Teaching Hospital and General Hospital Marina Lagos and more than double the time recorded in a study of the
General outpatient department of Usman Dan Fodio University Sokoto all of which also use the block appointment system. ${ }^{6-8,13}$

Although several factors may have contributed to the excessively long waiting time including shortage of staff, and late commencement of consultation by doctors, we believe the block appointment system played a major role. Scheduling all the patients for the day's clinic for 7.30 am or $8.00 \mathrm{am}$ in spite of the awareness that some of the patients may not be seen until well after noon requires that many of the patients wait for several hours. In this study some of the patients waited for 440 minutes ( 7.3 hours) before seen.

The excessively long waiting time is not only a waste of the patient's time but an avoidable loss of man work hour that could be better used for productivity and national development. Several studies have shown that waiting time is one of the major factors affecting patient's satisfaction with services. ${ }^{11}$ In our study, majority of the respondents $(86.2 \%)$ who were dissatisfied with the hospital's services cited long waiting time as the main factor responsible for their dissatisfaction.

Majority of our respondents were unhappy with the time they spent waiting to see a doctor and we believe the appointment system practiced in the hospital may have contributed to the long waiting time 
experienced by the respondents. We do not know why the Hospital practices the single block appointment system that obviously wastes patient's time and is at variance with the preference of their patients. Further studies are needed to understand this. A scattered (time specific) appointment system however, will reduce waiting time since patients will arrive at their scheduled time and see their doctor at that time or a few minutes later. This will eliminate the need to arrive hours before the commencement of the clinic just to take an early position on the queue.

One limitation of this study is that different observers recorded the waiting time in the different clinics and some may be more prone to distraction than others leading to inter observer variation. To reduce this error, subjects were requested to note the time they entered the consulting room or alert the observer when they were called in if they do not have a watch or cell phone.

\section{Conclusion}

Jos University Teaching Hospital practices single block appointment system that results in long patient waiting time at the out-patient clinics. Urgent action is needed to change this practice that contributes to patient's dissatisfaction. Management should work with the scheduling officers and doctors to commence time specific appointment system so that patients know at the time of booking, when they are to see their doctor and get to the clinic at that time or a few minutes earlier.

Acknowledgement: We wish to thank Dr Lenz Okoro, Dr JeffreyIdogho and Dr AhguOvye who assisted with the data collection.

\section{References}

1. TGMEDS. The Patients Charter and you - a Charter for England 2004.

Available from

http://www.tgmeds.org.uk/patientscha rter.html.(Accessed Jan 18, 2018)

2. Press Ganey Associates, Inc. Pulse report. 2009: Medical practice-Patient perspectives on American health care. (2009). Available from http://pressganey.com. Accessed Jan 18,2018

3. Michael M, Schaffer SD, Egan, PL, Little BB, Pritchard PS. Improving wait time and patient satisfaction in primary care. J Healthc Qual. 2013;35(2):50-60.

4. Yeddula V R., "Healthcare Quality: Waiting Room Issues" (2012). Industrial and Management Systems Engineering - Dissertations and Student Research. Paper 29. Cited 2014 November 3. Available from: http://digitalcommons.unl.edu/imsedi ss/29. (Accessed Dec 15,2017)

5. Umar I, Oche MO, Umar AS. Patient waiting time in a tertiary health institution in Northern Nigeria. J Public Health Epidemiol. 2011;3(2):78-82.

6. Oladapo OT, Iyaniwura TA, SuleOdu AO. Quality of antenatal services at the primary care level in Southwest Nigeria. Afr J Reprod Health 2008;12(3):71-92.

7. Adesanya T, Gholahan O, Ghannam $\mathrm{O}$, et al. Exploring the responsiveness of public and private hospitals in Lagos. J Public Health Res. 2012; 1: e2. doi:10.4081/jphr. 2012.e2

8. Campbell PC, Olufunlayo TF, Onyenwenyi AO. An assessment of client satisfaction with services at a model primary health care centre in Ogun State, Nigeria. Nig Q J Hosp Med. 2010;20(1):13-8.

9. Obiechina GO, Ekenedo GO. Factors affecting utilization of university health services in a tertiary institution 
in South-West Nigeria. Niger J Clin Pract. 2013;16(4):454-7.

10. Uchendu OC, Ilesanmi OS, Olumide AE. Factors influencing the choice of health care providing facility among workers in a local government secretariat in South Western Nigeria. Ann Ib Postgrad Med. 2013; 11(2):87-95.

11. Yeboah E, Thomas M. A costeffective way of reducing outpatient clinic waiting times: How we did it. The Internet Journal of Healthcare Administration 2009;7(1) Cited Dec 18, 2016. Available from: https://ispub.com/IJHCA/7/1/11900. (Acccessed Dec 15,2017)

12. Pillay DMS, Ghazali RJ, Abd Manaf NH, et al. Hospital waiting time: the forgotten premise of healthcare service delivery? Int J Health Care Qual Assur. 2011; 24(7):506-522.

13. Akinyinka MR, Adebayo BI, Wright $\mathrm{KO}$, Adeniran A. Client waiting time in an urban primary health care centre in Lagos. Journal of Community Medicine and Primary Health Care. 2016;28(1):17-24.

14. Johnson WL, Rosenfeld LS. Factors Affecting Waiting Time in Ambulatory Care Services. Health Services Research. 1968;3(4):286295.

15. Committee on Optimizing Scheduling in Health Care; Institute of Medicine; Kaplan G, Lopez MH, McGinnis JM, editors. Transforming Health Care Scheduling and Access: Getting to Now. Washington (DC): National Academies Press (US); 2015 Aug 24. 2 , Issues in Access, Scheduling and Waiting Time. Available from: https://www.ncbi.nlm.nih.gov/books/ NBK316141/.(Accessed Jan 20, 2018)

16. Araoye MA. Research methodology with statistics for health and social sciences. 1st ed. Illorin: Nathadex Publishers; 2003. Sample size determination; pp. 115-21.

17. Oche M, Adamu H. Determinants of Patient Waiting Time in the General Outpatient Department of a Tertiary Health Institution in North Western Nigeria. Annals of Medical and Health Sciences Research. 2013;3(4):588-592. doi:10.4103/2141-9248.122123.

18. Mardiah FP, Basri MH. The analysis of appointment system to reduce waiting time at Indonesia's public hospital. Human Resource management Research. 2013;3(1);2733

19. ThacherT.Out Patient waiting time in Jos University Teaching Hospital. Highland Medic Res Journ. 2005; 3(1): $36-42$ 